\title{
Memórias Que Reinscrevem: O Uso da Memória na Reconstrução Identitária do Quilombo Baixa Grande
}

\author{
Memorias que reinscriben: el uso de la memoria en la reconstrucción identitaria en el \\ Quilombo Baixa Grande
}

Memories that re-inscribe: the use of memory in the identity reconstruction in Quilombo Baixa Grande

Edna Balbina dos Anjos dos Santos ${ }^{1}$

\section{RESUMO}

O trabalho discute memória como ferramenta de reconhecimento da identidade. Se trata da auto atribuição de comunidade negra, onde os questionamentos dos mais jovens e o conhecimento dos mais velhos se alinharam ressignificando a identidade quilombola.

Palavras-chave: Memória. Identidade. Comunidade. Negra. Quilombola.

\section{RESUMEN}

Este trabajo discute la memoria como herramienta de reconocimiento de la identidad, enfocando la auto identificación como comunidad negra, en la cual los cuestionamientos de los jóvenes y el conocimiento de los viejos se alinearon, resignificando la identidad quilombola.

Palabras-clave: Memoria. Identidad. Comunidad. Negra. Quilombola.

\section{ABSTRACT}

This paper addresses the role of memory as a tool of identity recognition. If focuses on the self-identification of an Afro-Brazilian community, in which the questions posed by the youth and the knowledge of the elders have aligned themselves, presenting new meanings to the quilombola identity.

Keywords: Memory. Identity. Community. Afro-Brazilians. Quilombola.

Submetido em: 16/08/2019 - Aceito em: 19/12/2019 - Publicado em: 28/12/2019.

${ }^{1}$ Quilombola, moradora do Quilombo Baixa Grande, graduanda no curso de graduação em Ciências Sociais do Centro de Artes Humanidades e Letras da Universidade Federal do Recôncavo da Bahia. Participou como pesquisadora no processo de auto atribuição da comunidade de Baixa Grande como remanescente quilombola. 


\section{Breve Reflexão Sobre Raça e Formação Comunitária}

Falar sobre raça se torna exercício que exige muita reflexão, por que a idealização de raça varia a partir do local em que se instala, é uma ideologia criada dentro e fora do "espaço negro" (SANSONE, 1996), é muito importante que pensar negritude aconteça com base em recortes nos situando geograficamente, refletindo conjuntura socioeconômica, desenvolvimento da identidade negra e discursos oficiais - Estado, Igreja e politicas (SANSONE, 1996) e o lugar onde estamos. Esse ensaio vem na perspectiva de defender a memória como ferramenta fundamental no processo de reconhecimento dos valores do povo negro na diáspora, fazendo uma discussão sobre o uso da mesma na comunidade de Baixa Grande ${ }^{2}$.

“Eles mediam a terra apontando com o beço e diziam: daqui até lá é meu de lá pra lá é teu”.

“Baixa Grande e Baixa Pequena 4 são divididas pela lagoa, mas as famílias são as mesmas".

"Chico Véi eu conheci velhinho, mas ele foi o primeiro morador daqui”.

"Chamava fazenda grande a casa de Chico Véi, ali de frente pra lagoa, moravam os filhos e um bocado de neto morou lá também”.

"Isso aqui tudo era mato, tinha uma mata virgem”.

\footnotetext{
${ }^{2}$ Comunidade rural negra localizada no município de Muritiba Recôncavo da Bahia. Usando os recursos da oralidade e da memória ouve a descoberta de ser Chico Véi o primeiro habitante da comunidade.

${ }^{3}$ Os lábios

${ }^{4}$ Baixa Pequena é uma comunidade vizinha que de acordo aos relatos, sua formação se deu no mesmo período que Baixa Grande. Com os recursos da memória oral, foi possível saber que Vitória foi a primeira moradora da comunidade. Filhos e filhas de Vitória se casaram com filhos e filhas de Chico Véi possibilitando que hoje moradores de Baixa Grande e Baixa Pequena tenham laços de parentesco muito fortes.

${ }^{5}$ Chico Véi é Francisco José dos Santos, que segundo a oralidade foi o primeiro morador da comunidade de Baixa Grande, transformando um espaço antes mata virgem em comunidade negra ligada pelos laços sanguíneos, e não se sabe ao certo de onde veio. Com os relatos feitos na pesquisa foi possível analisar que os moradores de Baixa Grande em sua maioria são netos, bisnetos e tataranetos de Chico Véi, sendo poucas pessoas que não fazem parte do parentesco e que chegaram à comunidade há pouco tempo. De acordo aos relatos Chico Véi morreu muito velho com mais de 100 anos de idade, tinha costumes bem diferentes do que é vivido hoje em relação ao convívio com as fontes naturais, a exemplo, acendia fogo de lenha na sala de casa para se aquecer e falava muito pouco, o sustento de sua casa era tirado da lagoa existente na comunidade.
} 
Os fragmentos ${ }^{6}$ anteriores são trazidos aqui na intenção de nos aproximar da discussão sobre o uso da memória como meio para o processo de formação da identidade. Scott (2008) quando usa seus argumentos a favor da memória na preservação de documentos e da história considerando que a memória é acessada conforme a necessidade de que se faça tal exercício como contra-argumento à história tradicional, alerta que a memória é aberta, seletiva, fragmentária, não linear ao contrário da história (SCOTT, 2008) que se fecha em padrões e nas relações de poder. A memória como exercício de re-memorar para remontar os aspectos da nossa vida juntos, tornar visível o que foi obscurecido, o que foi excluído, o que foi esquecido (SCOTT, 2008).

No ano de 2015 um grupo de jovens ${ }^{7}$ moradoras (res) da comunidade de Baixa Grande decidiu iniciar uma pesquisa para o processo de demarcar a história da comunidade a partir da memória dos mais velhos e com o registro dos relatos, entrar com o processo do pedido de reconhecimento como comunidade remanescente de quilombo, partindo da ideia do quilombo como lugar residual (ALMEIDA, 2011), que guarda resquício da colonização, e assim como pontuado por Pinho (2004) tomando a natureza como forma de identificação, clamando por uma identidade natural, que não pode ser tirada (PINHO, 2004) assim como seus traços fenotípicos tão discriminados.

O grupo no início recorreu ao exercício inverso na apropriação de sua imagem, fazendo uso desta para o processo político usando a cor da pele e a historicidade social como demarcador para a construção da identidade coletiva - dizendo: "se é pela nossa pretidão que nos discriminam e nos isentam de direitos é a partir dela que faremos o caminho contra", transformando atributos do corpo negro, previamente tidos como negativos, em positivos. Não

\footnotetext{
${ }^{6}$ As citações são resultado da pesquisa realizada na comunidade onde algumas pessoas mais velhas relataram seu conhecimento sobre a mesma, todos os fragmentos que aparecem nesta parte do trabalho foram dos relatos de netos de Chico Véi, alguns já falecidos no período da construção deste ensaio.

${ }^{7}$ No inicio da pesquisa duas das jovens eram estudantes da Universidade Federal do Recôncavo da Bahia no curso de História e de Museologia.
} 
se trabalhando mais nos paradigmas no qual eles foram originalmente gerados (HALL, 2003), no entanto, numa perspectiva contra hegemônica.

Com o desenrolar da pesquisa, as conversas com os mais velhos, o acesso ao conhecimento instalado na memória que cobra a expressão fundante no resguardo do passado (SCOTT, 2008) e o uso de leituras antropológicas determinaram outro conceito para a formação da identidade coletiva para o pedido de reconhecimento, se valendo dos significados culturais, espirituais e a relação familiar para estabelecer o desejo comum do reconhecimento identitário, lembrando que concordo com Sansone quando diz que: "a criatividade das culturas negras no Brasil deve interessar mais que vestígios de africanismos, pois a África é reinventada pelo povo negro e isso por razões políticas, pois foram séculos de tentativas de desmanche da cultura africana no Brasil" (SANSONE, 2007), as dinâmicas destas reinvenções foram associadas a um processo político coletivo, pois a África é reinscrita no corpo (PINHO, 2004) e se apresenta de maneiras múltiplas conforme assumida pelos sujeitos.

\section{A Memória Como Fator Emancipatório}

O uso da oralidade foi um fator cultural na vida de jovens moradores de Baixa Grande na infância, as histórias do colonizador foram transferidas por gerações entre moradores e moradoras da comunidade, a falta do conhecimento da escrita, o analfabetismo dos mais velhos os fazia "letrados" a partir das histórias que dominavam nos registros memoriais pela quantidade de vezes que repetiam o discurso do colonizador, em escalas menores ou quase nunca a própria história era contada, recontada ou revisitada, a história dos despossuídos, desprezados e destituídos (SCOTT, 2008) que assim se fizeram pela dominação.

A dinâmica do uso da memória como instrumento emancipatório é recente, a exemplo, é no decreto 4887/03 que as comunidades quilombolas recebem o direito de si auto atribuir enquanto tal a partir da auto avaliação e reconhecimento identitário como quilombolas. O decreto confere que são as articulações políticas, culturais e auto atribuição, além da história de vida construída na comunidade que garante aos sujeitos a identidade quilombola, são as práticas de resistência, manutenção e reprodução do seu modo de vida característicos num determinado lugar (ARRUTI, 2008) que lhe garante direito e autonomia em assumi a identidade quilombola. 
Antes não era importante falar sobre as experiências e formas de organização destas e na comunidade de Baixa Grande se dava igualmente, as histórias responsáveis por formar os sujeitos da comunidade não se remetia aos seus ancestrais na busca por construir uma identidade firmada nos valores de um povo, inclusive por que a história do povo negro e especificamente dos quilombos eram veladas e se alertava para uma história de marginalidade. Sempre historias depreciativas sobre o negro foram criadas, inventadas e socializadas pelo racismo que por ser estrutural na sociedade brasileira muitas vezes convence os discriminados de que neles reside a culpa ou, ao menos, a responsabilidade pelos atos discriminatórios (PINHO, 2004) isso encarado como natural e aceito como se existisse uma vontade para além do controle humano sobre a opressão, como algo que girasse em torno da vontade divina.

Neste enfoque, a pesquisa na comunidade seguiu questionando aos mais velhos sobre suas organizações ancestrais, a convivência, organização familiar, razões que fizeram de Baixa Grande uma comunidade estigmatizada no recôncavo da Bahia por ser "terra de preto", como se assim não fosse as demais comunidades muritibanas, como se a identidade estivesse de fato inscrita no corpo como pontuado por Patrícia Pinho (pag. 152), estabelecendo lugar central à cor da pele que alerta para o encontro e o confronto entre iguais e diferentes em um processo político que define aliados e inimigos (PINHO, 2004) numa relação marcada pela desvalorização conforme a pigmentação que confere ao sujeito quanto mais pigmentado o status de mais preto, desse modo, atribuindo sentidos à pessoa, numa relação onde o uso dos termos tem significados (PINHO, 2004) e cumpre o papel de hierarquizar.

Em resposta a estes questionamentos o processo de re-memoração possibilitou o conhecimento da formação da comunidade iniciada por Chico Véi, observando a existência da recordação e do esquecimento na comparação das falas onde fatos relatados por determinada pessoa não aparecia na fala de outras. Este exercício possibilita o entendimento de que a memória é carregada desta função de recordar o necessário às suas identificações, - conectando ou desconectando - no jogo realizado pelos mais velhos, conectando os mais jovens ao passado coletivamente construído em Baixa Grande e desconectando-os das lembranças julgadas desnecessárias de serem acessadas em determinado momento, importando ainda como um jogo 
político do interlocutor que se trata aqui de protagonista, que se comporta como sujeito da história que relata e que ainda assim tem a memória marcada pelas gerações que os antecederam e da mesma forma gerações futuras serão marcadas, irão usar este mecanismo no exercício de continuidade e descontinuidade ao qual Scott (2008) faz alusão. E ainda me comprometo em pensar que a desconexão com memórias passadas pode realizar função de silenciamento da dor, se contextualizarmos a existência do negro no período escravocrata.

A partir da experiência da pesquisa na comunidade, a fala dos moradores sobre como a organização destes caracteriza a existência do grupo fortalecido de relações internas possibilitando ainda que fosse explicado como existe a dissemelhança com comunidades circunvizinhas que aparentam semelhança. Por tanto a analise mais detalhada das relações existentes garante a percepção de que a formação da comunidade de Baixa Grande é carregada de outros fatores distintos que não se resume aos traços fenotípicos apontados como estigma, a exemplo, manifestação da cultura, religiosidade, festejos, ligação familiar estes fatores apresentam um ritmo diferenciado que só se revela no encontro com o outro (BARTH, 1998), com o diferente, se tratando de um modelo especifico de organização social. Uma organização social segue a via da categorização, onde sujeitos são enquadrados em grupos que correspondam significados e valores iguais a determinada coisa. É interessante observar que a categorização em grupos acontece por parte do sujeito e também do outro, é de alguma forma a partir de como o outro o percebe que sua identidade étnica é construída, como apontado por Barth as identidades são categorizadas pelo outro no sentido organizacional:

Uma atribuição categórica é uma atribuição étnica quando classifica uma pessoa em termos de sua identidade básica, mas geral, presumivelmente determinada por sua origem e seu meio ambiente. $\mathrm{Na}$ medida em que os atores usam identidades étnicas para categorizar a sim mesmos e outros com objetivo de interação, eles formam grupos étnicos neste sentido organizacional (BARTH, 1998).

Se a categorização dos sujeitos tem por finalidade a organização de grupos culturais e sociais, o exercício desenvolvido na relação entre a comunidade já citada e suas vizinhas se 
desenvolveu de maneira que o agenciamento destas identidades é usado como mecanismo de opressão determinada a partir das heranças históricas e das categorias sociais estabelecidas na comunidade e nas comunidades vizinhas sobre o que é ser preto e o que não é, de modo que aparece nessa relação a dessemelhança dos sujeitos não pretos retintos com os que assim são, por isso para mim é importante falar da cor de pele retinta no inicio do texto, valendo análise de que essa distinção não os imuniza de serem vítimas de racismo em outros contextos sociais, pois o contato com outros diferentes é que dar origem à diferença, a diferença é aquilo que o outro é (SILVA, 2003) e não é perceptível em mim. .

Os conflitos presentes hoje são de alguma forma, identificados no acesso à memória dos mais velhos como método utilizado para subordinação social dos moradores da comunidade desde o passado. Ser morador da comunidade de Baixa Grande garante significado ainda pela cor da pele, estando os moradores de Baixa Grande presos nesta armadilha na qual a linhagem e origem comum, juntam-se a cor e raça para definir a identidade coletiva, inclusive para determinar "os de dentro" e "os de fora" do grupo (PINHO, 2004), onde as marcas presentes no corpo reproduzem desigualdades (PINHO, 2008) onde fronteiras sociais (BARTH, 1998) demarcam o acesso e o não acesso a espaços, modos de vida, educação, saúde dentre outros direitos básicos.

A demarcação entre ser ou não moradora (o) da comunidade de Baixa Grande não gera conflitos se pensado apenas como demarcador demográfico, assim como apontado por Silva (2003), se trata de classificação entre quem é e quem não é, entre mim e eles, os de cá e os de lá e com essa divisão o mundo social é classificado e esse exercício é fundante na construção da identidade, o conflito está na demarcação de fronteiras como referido pelo mesmo autor ("estes pertencem/aqueles não - bons/maus - puros/impuros - desenvolvidos/primitivos" Silva, 2003). O questionamento ganha forças quando a classificação hierarquiza identidades, criando subalternidades, pois o ato de classificar significa deter o privilégio de atribuir diferentes valores aos grupos assim classificados (SILVA, 2003) desta tensão que partimos na inquietação a respeito da identificação dos moradores de Baixa Grande. A hierarquia criada pelos grupos que os classificaram como inferior valeu como subsídios para uma realidade social de discriminação e falta de acesso como já pontuado. 
O processo ao qual chamo atenção, remota ao fato ocorrido na formação de blocos afro na Bahia, estudados por Patrícia Pinho, onde a autora diz que a transformação se deu a partir da criação de novas representações que superassem a imagem do negro. Foi preciso ressignificar e representar as imagens do negro de modo novo (PINHO, 2004), a comunidade trilhou o caminho do re-memoramento de elementos étnicos para fortalecer a existência do grupo, esse exercício foi possível ainda a partir da identificação na historicidade de outras comunidades do recôncavo já reconhecidas como remanescente de quilombo e que possuía atributos muito semelhantes à comunidade de Baixa Grande, o contato possibilitado pelo encontro na Universidade Federal do Recôncavo da Bahia com outras (os) quilombolas universitárias (os) se tornou ferramenta para enriquecer a construção identitária.

Partindo da questão do enfoque da memória para refazer a história da comunidade a partir das narrativas, foi possível observar na tradição da comunidade valores significativos de um grupo étnico organizado a mais de um século e que começou a existi com a chegada de Chico Véi. A construção de sua casa iniciou a primeira habitação e foi seguida por moradias de filhos, netos e hoje a comunidade tem uma população estimada em cerca de 300 famílias interligadas pelos laços sanguíneos. Tomar conhecimento destes fatos e publiciza-los foi possível a partir da iniciativa de um grupo de pessoas que inquietos com a classificação que lhe era permitida em contexto geográfico ao qual estão inseridos resolveram fazer outro movimento com a identidade que sempre lhe foi atribuída.

Com isso, a comunidade buscou problematizar a opressão e o descaso que sempre passaram e revelaram o que o grupo possuía em comum, dizendo ${ }^{8}$ : somos uma comunidade quilombola, nossos (as) ancestrais foram escravizados (as) no recôncavo da Bahia, nossa história não é contada nos livros didáticos, não recebemos cuidados em saúde especifica, não temos educação de qualidade e reivindicamos nossos direitos. Com esse exercício inverso fazendo novas representações da imagem do negro, garantindo orgulho e dignidade (PINHO, 2004) para as pessoas da comunidade, foi possível reivindicar políticas sociais. A identidade como é possível

\footnotetext{
${ }^{8}$ Fiz parte da mobilização e foi deste pressuposto que partimos.
} 
observar foi usada pelo grupo de forma política, já que se trata de um elemento socialmente construído (SILVA, 2003) ela se refez no ato do confronto com o que era atribuído ao grupo em questão.

No ano de 2016 a certificação da comunidade de Baixa Grande como remanescente de quilombo foi deferida pela Fundação Cultural Palmares, órgão do governo federal responsável pela emissão da certificação e acompanhamento das comunidades. É importante alertar que houve mobilização por parte dos moradores da comunidade para que a identidade coletiva se desse em comum acordo, ou seja, o pedido de reconhecimento foi firmado em abaixo assinado onde maioria dos moradores da comunidade assinou formalizando auto atribuição.

Desse modo podemos alertar para a reinvenção de dois atributos antes essencialistas sobre comunidades negras no Brasil e aqui se tratando de uma comunidade especifica, levaremos em consideração que passam a agir com outras características: primeiro pensar a figura negra em Baixa Grande como algo inferiorizado pelos de fora, isento de saber e de valores, associados à feiura e sujeira, comparados a animais (PINHO, 2004), valendo lembrar que se trata de categorias hierarquizantes e a partir disso geram opressão e desigualdade (HALL, 2003) e que uma vez ressignificada esta identidade pelo grupo, percorre outro viés para um posicionamento político na busca por respeito e por dignidade humana já que ao negro isso foi historicamente negado. E segundo, vale pensar como a categoria quilombo é do mesmo modo reconstituída sendo transferida da relação com marginalidade para espaço de resistência (ALMEIDA, 2011) inscrevendo outras histórias fazendo uso destes pressupostos, pois em locais históricos e a partir dos discursos é que se constroem as identidades (SILVA, 2003) reconhecendo a diferença como posicionalidade para a construção da identidade, mas entendendo que ela nunca deve agir como hierarquias opressivas, apesar de compreender que as identidades existem a partir do outro, ainda que seja um outro silenciado, a construção da identidade revela poder (SILVA, 2003) até mesmo porque se trata da observação e apontamento de diferenças.

\section{Considerações Finais}

Neste ensaio o esforço feito foi na intenção de discutir de forma objetiva como que a construção da identidade de grupos étnicos recebe influência de grupos diferentes para sua formação e 
reconhecimento e ainda procurei traçar um panorama a cerca da substituição dos valores atribuídos a determinados grupos e que recebem outras características em determinados momentos e contextos históricos, concebendo a ideia de que a identidade nada tem de estática, ela se movimenta conforme os acessos desejados por sujeitos ou coletivos.

Essa discussão de forma subjetiva tocou minha visão sobre o tema identidade uma vez que pelas experiências que me foram possíveis no decorrer da vida me fez refletir até determinado momento que a identidade nada mais era além daquilo que o outro apontava sobre mim. As leituras e discussões sobre a visão de alguns pensadores, a exemplo Stuart Hall, Patrícia de Santana Pinho, Tomaz Tadeu da Silva, dentre outros teóricos acessados na academia abriu possibilidades para compreender que o campo da identidade é movediço e ainda assim depende da contribuição do outro sobre nós e esse é um fator que ocorre de formas variadas. No caso da atribuição do outro sobre a comunidade quilombola de Baixa Grande isso se deu de forma negativa por muitos anos e só o movimento de reinvenção de valores, reivindicação por reconhecimento é que garantiu uma visão de positividade sobre essa identidade por muito marginalizada.

Outro ponto que busquei discuti, porém de forma breve é como o elemento cor é relevante no contexto comunitário e esse é um fator que não poderia ser descartado, pois foi a partir e baseado nele que a pesquisa sobre a comunidade trilhou, considerando que os sujeitos de fora nem sempre são brancos, mas sendo de pele clara, a cor da pele garante significados para a diferenciação, o sujeito negro em Baixa Grande é marcado pela negritude e procurando ser mais eficaz na explicação, ele é marcado pela pretidão no ato do nascimento, sem possibilidade de transitar entre os dois mundos (PINHO, 2008) do modo que é possibilitado a miscigenados.

Para outras discussões e ainda acessando os mesmos referenciais teóricos teríamos nos valido de acontecimentos culturais, o uso de plantas medicinais, benzedeiras, devoções, organização familiar, pois a identidade étnica de Baixa Grande percorre estes valores, por tanto aqui nos reservamos à questão da identidade e suas formas de se inscrever no corpo a partir do contato com o outro. 


\section{Revista Docência e Cibercultura}

\section{Referências}

ALMEIDA, Alfredo Wagner Berno de. Quilombos e as Novas Etnias - Manaus: UEA Edições, 2011.

ARRUTI, José Mauricio. "Quilombos”. Raça: novas perspectivas antropológicas / Lívio Sansone, Osmundo Araújo Pinho (organizadores). - 2 ed. rev. Salvador: Associação Brasileira de Antropologia: EDUFBA, 2008. 447 p.

BARTH, Fredrik. Grupos Étnicos e suas Fronteiras. In: POUTIGNAT, Philippe e STREIFFFENART, Jocelyne. teorias da etnicidade. São Paulo: Unesp, 1998, p. 185-227.

HALL, Stuart. “Quem precisa de identidade?”. In: SILVA, Tomaz Tadeu (Org.). Identidade e diferença: a perspectiva dos Estudos Culturais. Petrópolis: Vozes, 2003.

PINHO, Osmundo. A Antropologia no Espelho da Raça, 2008.

PINHO, Patrícia de Santana. “A África no corpo”. In: Reinvenções da África na Bahia. São Paulo: Annablume, 2004.

PINHO, Patrícia de Santana. "Nascer preto, tornar-se negro, conceber-se humano". In: Reinvenções da África na Bahia. São Paulo: Annablume, 2004.

SANSONE, Lívio. Nem Somente Preto ou Negro: O Sistema de Classificação Racial no Brasil que Muda. Afro-Ásia, n 18, pp 165 - 187. 1996.

SANSONE, Lívio. Negritude Sem Etnicidade: O local e o global nas relações raciais e na produção cultural negra do Brasil. Tradução: Vera Ribeiro - Salvador: Edufba; Pallas, 2007.

SCOTT, David. Introducción: Sobre las arqueologías de la memoria negra. small axe 26. June 2008. p v-xvi

SILVA, Tomaz Tadeu. A Produção Social da Identidade e da Diferença. In: SILVA, Tomaz Tadeu (Org.). Identidade e diferença: a perspectiva dos Estudos Culturais. Petrópolis: Vozes, 2003. 